\title{
Immunological Assay for the Diagnosis of Coeliac Disease: Interaction between Purified Gluten Fractions
}

\author{
A. ASHKENAZI, ("i!) S. LEVIN, D. IDAR, A. OR, I. ROSENBERG, AND Z. T. HANDZEL \\ The John Askin Department of Pediatric Research and the Department of Pediatrics, A. Kaplan Hospital, Rehovot. \\ Israel, affiliated with the Hebrew University, Hadassah Medical School, Jerusalem, Israel
}

\begin{abstract}
Summary
Increased leukocyte migration inhibition factor (LIF) production by coeliac patients' lymphocytes is a reliable immunologic test for gluten-sensitive coeliac disease providing the small peptide subfractions of gluten are used as mitogens. To investigate discrepancies in results obtained in various published studies, subfractions (B2 and B3) of crude gluten peptic tryptic digest [Frazer's fraction III (F3)] were used singly and in combination as mitogens in coeliac patients and compared in various doses with $F 3$. There was significant increased production of LIF with B2 or B3 when tested separately as compared to a mixture of $\mathrm{B2} \pm \mathrm{B} 3$ or to $\mathrm{F3}$. LIF production with B2 or B3 was $23.7 \pm 6.9 \%$; with B2 + B3, it was $10.65 \pm 14.7 \%(t=4.05 ; P<0.0005)$; and with $\mathrm{F} 3$, it was 9.2 $\pm 10.2 \%(t=5.8 ; P<0.0005)$. There was no difference in the response between $\mathrm{B} 2+\mathrm{B} 3$ and $\mathrm{F3}(t=0.4 ; P=0.32)$. Studies of LIF production following stimulation by various doses and combinations of gluten mitogens in the same patient gave the best results with $\mathrm{B} 2$ or $\mathrm{B3}$ in $10 \mu \mathrm{g}$ doses, with a tendency to less LIF production with higher dosages or combinations of $B 2+B 3$ or $F 3$, even to abolition of LIF production in some coeliac cases. The LIF assay is a reliable immunologic test for gluten sensitivity, providing the $B 2$ or $B 3$ subfractions are used as mitogens.
\end{abstract}

\section{Speculation}

It is speculated that subfractioning of Frazer's fraction III of a peptic tryptic digest of gluten into smaller peptides which are used as mitogens allows for the detection of an increased number of immunogenic sites on mononuclear cells. When these small fractions, B2 and B3, are used as mitogens, lymphocytes from cases of coeliac disease produce increased amounts of leukocyte migration inhibition factor. Mixing these antigens diminishes leukocyte migration inhibition factor production, probably due to masking of antigenic sites.

The diagnosis of coeliac disease, which in children is a common malabsorbtion syndrome caused by intestinal sensitivity to gluten. usually requires repeated small bowel biopsies in addition to a battery of other biologic and biochemical tests (4). The first biopsy is performed while the patient is symptomatic and consuming a regular diet. It is repeated after a period of gluten-free diet when symptoms have abated, and a third biopsy is done after rechallenge with gluten. While searching for more specific tests to obviate the need for these repetitive invasive biopsies, we demonstrated that peripheral blood lymphocytes from $95 \%$ of coeliac patients tested responded to stimulation with gluten subfractions by producing increased amounts of leukocyte migration inhibition factor (LIF) (1). This finding was contrary to that of Bullen and Losowsky (3) who found that only $40 \%$ of their patients responded to a crude gluten peptic tryptic digest, Frazer's fraction III (F3). To try to resolve this discrepancy, we compared LIF production in coeliac patients and normal individuals in response to stimulation with the individual gluten subfractions B2 and B3 with the response to various mixtures of these two subfractions as well as with the original $\mathrm{F} 3$ fraction.

\section{MATERIALS AND METHODS}

Studies were made on two test groups. Group I was comprised of 28 biopsy-proven coeliac patients of whom 9 were on regular diet during the investigation, 14 were on a strict gluten-free diet, and 5 occasionally consumed gluten. The patients $(15$ male and 13 female) ranged in age from 6 months to 17 years.

Group 2 was comprised of 9 normal children and adults selected from the staff or from patients undergoing minor elective surgical interventions or admitted for observation after minor trauma. To all participants, the purpose of the blood examination was explained, and informed consent was then obtained.

F3 (29 g) derived from $200 \mathrm{~g}$ of gluten (Sigma Chemical Co., St. Louis, MO) was divided into four subfractions by dialysis against distilled water for 3 days with water changes every $24 \mathrm{hr}$ and then refractionated on a Sephadex G-50 column according to the method of Sikora et al. (9). The eluate consisted of four subfractions [B1 (3 g), B2 (7.3 g), B3 (2 g), and B4 (4.8 g)] for a total amount of $17.1 \mathrm{~g}$. The activity of each fraction was tested using lymphocytes from coeliac patients in the LIF assay: F3 and the subfractions B2 and B3 which elicited good LIF responses were subsequently used either separately or in combination in the assay.

LIF ASSAY

Peripheral blood leukocytes were separated on Ficoll-Isopaque gradients (Lymphoprep, Nyegaard \& Co., A/S, Oslo, Norway) as described by Boyum (2). Patients' lymphocytes were collected from the interphase, and their polymorphonuclear leukocytes were collected from the bottom phase of the gradient tube. Lymphocytes $\left(1 \times 10^{6}\right)$ were mixed with $3 \times 10^{6}$ polymorphonuclear leukocytes and centrifuged for $5 \mathrm{~min}$ at $1500 \mathrm{rpm}$, and the supernatant fluid was removed. The cells were resuspended in $0.075 \mathrm{ml}$ of M199 medium containing penicillin (100 units $/ \mathrm{ml})$, streptomycin $(100 \mu \mathrm{g} / \mathrm{ml})$, and $0.2 \%$ agarose (Seakem-MGI Biomedical Division of Marine Colloids Inc.).

In each case, two 10- $\mu$ l drops of the agarose-cell suspension were placed over each of four separate $10-\mu \mathrm{l}$ drops of $0.8 \%$ gelled agarose in a $5-\mathrm{cm}$ plastic Petri dish (Nunc, Denmark) as previously described (5). Four to six Petri dishes were prepared in this way for each lymphocyte assay according to the experimental design. To the first Petri dish, phytohemagglutinin $(8 \mu \mathrm{g} / \mathrm{ml}$; PHA Burroughs-Wellcome, England) was added, to the second, fraction B2 $(10 \mu \mathrm{g} / \mathrm{ml})$ was added, to the third, fraction B3 $(10 \mu \mathrm{g} / \mathrm{ml})$ was added, to the fourth, $5 \mu \mathrm{g}$ of $\mathrm{B} 2+5 \mu \mathrm{g}$ of $\mathrm{B} 3$ or $10 \mu \mathrm{g}$ of $\mathrm{B} 2+10$ $\mu \mathrm{g}$ of $\mathrm{B} 3$ were added, to the fifth, $50 \mu \mathrm{g}$ of $\mathrm{F} 3$ were added, and the sixth received no antigens (control). In some experiments, other combinations of subfractions were used, ranging from 2.5 to 50 
$\mu \mathrm{g}$, as well as $100 \mu \mathrm{g}$ and $200 \mu \mathrm{g}$ of F3. Each dish was covered with $2 \mathrm{ml}$ of M199 medium supplemented with the antigens as specified above with antibiotics and 10\% fetal calf serum (Grand Island Biological $\mathrm{Co}$.) and then incubated at $37^{\circ} \mathrm{C}$ under $5 \% \mathrm{CO}_{2}$ for $24 \mathrm{hr}(5,6)$.

Normally, leukocytes migrate out of the agarose droplet which has a defined edge into the medium, and within $24 \mathrm{hr}$, migration in the range of 250 to 400 micrometric unit is achieved. Migration was measured with an inverted microscope equipped with an ocular micrometric scale. Eight measurements were averaged from the edge of the two most suitable agarose droplets to the front line of migration in four quadrants of each drop. Percentage of migration inhibition was calculated as follows

$$
\left(1-\frac{\text { migration in test case (with antigen) }}{\text { migration in control (without antigen) }}\right) \times 100
$$

Migration inhibition of more than $15 \%$ was regarded as a positive response.

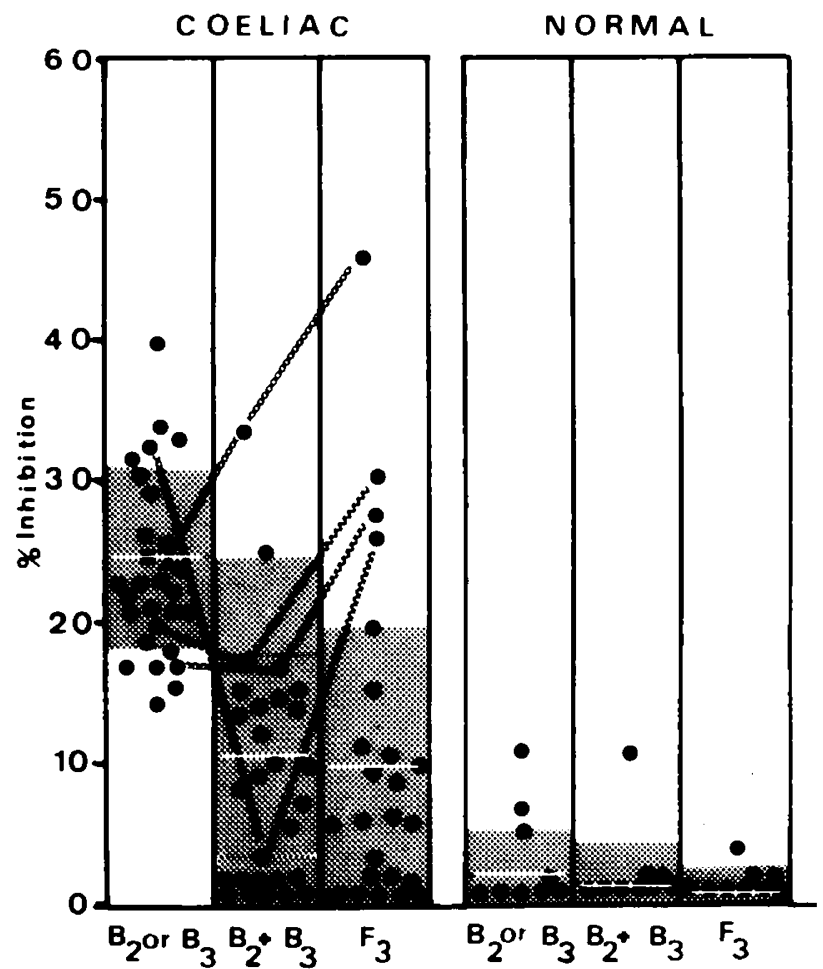

Fig. 1. LIF production by lymphocytes in coeliac patients and normal controls after stimulation by B2 or B3 subfractions of gluten or a combination of B2 + B3 or F3. Shadowed areas, mean \pm 1 S.D. Connecting lines, unusual responses in four patients. Column 3 contains only 25 patients because in three patients the F3 assay was not performed for technical reasons.

\section{RESULTS}

Preliminary experiments with the four fractions recovered after Sephadex G-50 chromatography showed that that neither fraction BI nor B4 inhibited cell migration (3.7 and 6.4\% inhibition, respectively) when tested on 5 coeliac patients. On the other hand, fractions B2 and B3 actively stimulated LIF production (22.4 and $23.4 \%$ inhibition, respectively). All functions were tested on the same patient in $10 \mu \mathrm{g}$ amounts.

The response of lymphocytes from the 28 coeliac patients and 9 controls to fractions B2 and B3 separately compared to a mixture of $\mathrm{B} 2+\mathrm{B} 3$ as well as the original fraction F3 may be see in Figure 1. There was a significant difference in LIF production with fraction B2 or B3; the highest response is recorded in the first column of Figure I tested separately as compared with LIF production by a mixture of $\mathrm{B} 2+\mathrm{B} 3$ or with $\mathrm{F} 3$. The mean percentage of migration inhibition of leukocytes from coeliac patients with B2 or B3 (using the highest figure of the two) was $23.7 \%$ (S.D., $\pm 6.9 \%$; S.E., $\pm 1.3 \%$ ); with $\mathrm{B} 2+\mathrm{B} 3$, it was $10.65 \%$ (S.D., $\pm 14.7 \%$; S.E., $\pm 2.8 \%$ ); with F3, it was $9.2 \%$ (S.D., $\pm 10.2 \%$ S.E., $\pm 2.1 \%$ ).

Statistical analysis of B2 or B3 as compared with B2 + B3 showed $t=4.05 ; P<0.0005 ; \mathrm{B} 2$ or B3 as compared with F3 showed $t=5.8 ; P<0.0005$, whereas no statistical significance was observed between the response of B2 $+\mathrm{B} 3$ as compared with F3 $(t=0.4 ; P=0.32)$.

In Figure 1, the connecting lines show an unusual response in 4 patients. One patient had a higher response to the B2 + B3 mixture as well as to fraction F3. Two other patients had higher response to $\mathrm{F} 3$ than to fractions $\mathrm{B} 2$ or $\mathrm{B} 3$. In one patient, the response was negative to $B 2+B 3$ and positive to $F 3$. The normal controls did not show any positive response to $\mathrm{B} 2$ or $\mathrm{B} 3$ or any response to $\mathrm{B} 3+\mathrm{B} 3$ and $\mathrm{F} 3$.

The response of lymphocytes from coeliac patients to fractions $\mathrm{B} 2$ and $\mathrm{B} 3$ in amounts from 5 to $50 \mu \mathrm{g}$ is shown in Figure 2. The

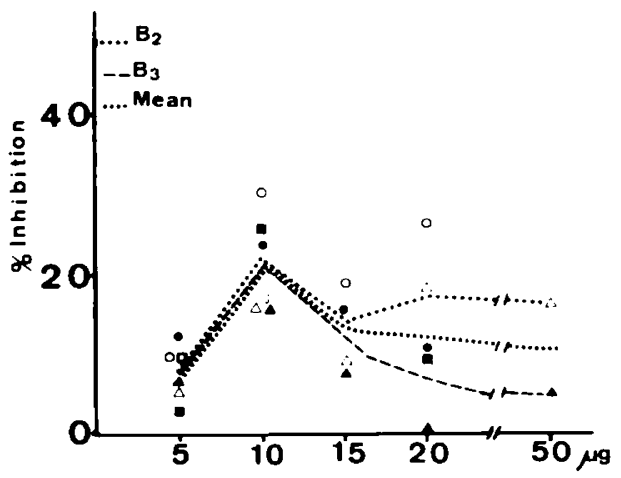

Fig. 2. LIF production by lymphocytes of 3 coeliac patients after stimulation by $5,10,15,20$, and $50 \mu \mathrm{g}$ of fractions $\mathrm{B} 2$ and $\mathrm{B} 3 . \bigcirc, \square, \triangle$, response to $B 2 ; \boldsymbol{Q}, \mathbf{\triangle}, \mathbf{A}$, response to $B 3 . \cdots$, mean of $B 2 ;----$, mean of B3; $\cdots \cdots$, mean of B2 and B3.

Table 1. Percentage of LIF from 7 coeliac patients using $10 \mu \mathrm{g}$ of B2 or B3 and varying amounts of B2 $+B 3$ and F3 as mitogens

\begin{tabular}{|c|c|c|c|c|c|c|c|c|}
\hline \multirow{2}{*}{$\begin{array}{c}\text { Mito- } \\
\text { gens }\end{array}$} & \multirow{2}{*}{$\begin{array}{c}\text { Amount } \\
(\mu \mathrm{g})\end{array}$} & \multicolumn{7}{|c|}{ Patient (\% inhibition) } \\
\hline & & 1 & 2 & 3 & 4 & 5 & 6 & 7 \\
\hline B2 & 10 & 27 & 16 & 20 & 33 & 22 & 18 & 29 \\
\hline B3 & 10 & 35 & 16 & 21 & 19 & -1 & 15 & 14 \\
\hline $\mathrm{B} 2+\mathrm{B} 3$ & $5+5$ & 15 & 0 & 19 & 13 & 16 & 9 & 24 \\
\hline$B 2+B 3$ & $2.5+7.5$ & 10 & 0 & - & - & - & - & 一 \\
\hline $\mathrm{B} 2+\mathrm{B} 3$ & $7.5+2.5$ & 18 & 0 & - & - & - & - & - \\
\hline $\mathrm{B} 2+\mathrm{B} 3$ & $10+10$ & 12 & - & 9 & 1 & - & 11 & 15 \\
\hline $\mathrm{B} 2+\mathrm{B} 3$ & $20+20$ & 0 & - & - & - & - & - & - \\
\hline F3 & 50 & 21 & 0 & 28 & 28 & 0 & 16 & 21 \\
\hline F3 & 200 & 11 & 0 & 3 & - & 0 & 25 & 20 \\
\hline
\end{tabular}

1 , not done. 
trend with both fractions B2 and B3 is similar, enhancement of LIF production by increasing the amount from 5 to $10 \mu \mathrm{g}$ with a tendency to decreased activity with 20 and $50 \mu \mathrm{g}$.

Table 1 shows results of experiments with combinations of B2 and $B 3$ on the same patient. The highest migration inhibition was obtained with fractions B2 and B3 tested separately (27\% and $35 \%$, respectively, in patient 1). Increasing concentrations of the two fractions in various combinations reduced the response until it was zero at $20 \mu \mathrm{g}$ each of B2 + B3. With lymphocytes from the second patient, a weaker reaction was obtained throughout, and all combinations of B2 + B3 totalling $10 \mu \mathrm{g}$ or more completely abolished the response. Increasing the amount of F3 from 50 to $200 \mu \mathrm{g}$ decreased the response of the lymphocytes from patients 1 and 3 . In patient 6 , the best response was obtained with $200 \mu \mathrm{g}$ of F3. In patients 3 and 4 , the response to $F 3$ was more pronounced than the response of the fractions. By increasing the amount of $F 3$ from $50 \mu \mathrm{g}$ to $200 \mu \mathrm{g}$ in patient 3, the response was abolished.

\section{DISCUSSION}

We have previously shown that the LIF assay is a reliable test for the diagnosis of coeliac disease in pediatric patients (1). Studies using the action of fractions of gluten on peripheral blood lymphocytes and measuring the effect of the stimulation by the increase of thymidine uptake were reported $(8,9)$. Our results confirm the above findings (1) in a different immunologic assay system. The test has proved to be positive in $95 \%$ of the patients examined. In the present report, we have tried to elucidate the discrepancy between our results and those of Bullen and Losowsky (3).

It seems that by increasing the mitogen dosage of the subfractions of gluten above a certain optimum in this assay, a decrease of the LIF response may be obtained in cases with coeliac disease (Fig. 2).

When combinations of B2 + B3 were examined and kept within the limit of $10 \mu \mathrm{g}$ total amount, decreased inhibition of migration was demonstrated as compared with B2 and B3 tested separately (Table 1). When amounts of B2 + B3 were further increased, there was a greater reduction in LIF production, possibly because both factors were at work antagonistically. By using F3 in increasing amounts, similar inhibitory results were noted, probably due to the fact that F3 is a combination of B1, B2, B3, and B4. Figure 1 depicts these conclusions graphically. Only 4 of 28 coeliac patients responded to B2 + B3 used together, and only 5 of 25 responded to F3. In 3 patients, F3 assay was not performed for technical reasons. A single patient responded better to $\mathrm{B} 2+\mathrm{B} 3$ and $\mathrm{F} 3$ and is an interesting exception. Holmes et al. (7) using 2 and $4 \mathrm{mg}$ of F3 obtained positive immunologic results in $40 \%$ of their adult patients. By using smaller subfractions of F3, we were able to get positive results in $95 \%$ of our pediatric patients (1). In this first study (1), we had a group of 12 children with gastrointestinal complaints, and the two "false" positive cases were children with history of diarrhea but with normal gastrointestinal mucosa. It is very important to follow and examine big groups of children with diarrhea to see what their response to fractions of gluten is going to be.

It seems that the results of these experiments can explain the discrepancies in various reported studies attempting to develop a specific, measurable, and reproducible immunologic test in coeliac disease using the stimulatory effect on lymphocytes of various gluten fractions. It seems too that fractionation of F3 into small peptides uncovers immunogenic sites, which are again masked by remixing of these fractions. We are trying to elucidate the mechanism of the interaction between the peptides present in the gluten fractions by purification and characterization of the active substances influencing both the lymphocytes and the intestinal mucosa of coeliac patients.

The LIF assay used in this manner is thus a useful procedure for the diagnosis of gluten-sensitive enteropathy. The antigens to be used for stimulation of the lymphocytes should be the small subfractions B2 and B3 of the peptic tryptic digest of F3.

\section{REFERENCES AND NOTES}

I. Ashkenazi, A., Idar, D., Handzel, Z. T., Ofarim, M., and Levin. S.: An in vitro immunological assay for diagnosis of coeliac disease. Lancet, 1: 629 (1978).

2. Boyum, A.: Separation of leukocytes from blood and bone marrow. Scand. J. Clin. Lab. Invest., 21: 1 (1968).

3. Bullen, A. W., and Losowsky, M. S.: Cell mediated immunity (CMl) to gluten fraction III (GF III) in adult coeliac disease (ACD) Gut, 17: 813 (1976).

4. Editorial: Confirming the diagnosis of coeliac disease. Br. Med. J., 2 (1975).

5. Hahn. T., Levin, S., and Handzel, Z. T.: Leucocyte migration inhibition factor (LIF) production by lymphocytes of normal children, newborns, and children with immune deficiency. Clin. Exp. Immunol., 24: 448 (1976).

6. Harrington, J. T., and Stastny, P. J.: Macrophage migration from an agarose droplet: development of a micromethod for assay of delayed hypersensitivity. J. Immunol., 110: 752 (1973).

7. Holmes, G. K. T., Asquith, P., and Cooke, W. T.: Cell mediated immunity to gluten fraction III in adult coeliac disease. Clin. Exp. Immunol., 24: 259 (1976).

8. Jos, J., Charbonnier, L., Mougenot, J. F., Mosse, J., and Rey, J.: Isolation and characterization of the toxic fraction of wheat gliadin in cocliac disease. Perspectives in coeliac disease, In: B. McNicholl. C. F. McCarthy, P. E. Fottzell: Proceedings of the Third Symposium on coeliac disease. September 19-21, 1977 (MPT Press Limited, Galway, Ireland, 1980).

9. Sikora, K., Anand, B. S., Truelove, S. C., Ciclitira, P. J., and Offord, R. E.: Stimulation of lymphocytes from patients with coeliac disease by a subfraction of gluten. Lancet, 2: 389 (1976).

10. Requests for reprints should be addressed to: A. Ashkenazi, Department of Pediatrics, Kaplan Hospital, P.O.B. I, Rehovot, Israel.

11. This research was supported in part by a grant to A. Ashkenazi by the combined research fund of the Medical School and Hadassah Hospital, Jerusalem. Israel. 12. Received for publication January 16, 1979

13. Accepted for publication April 17, 1979. 